\title{
Mechanisms of exertional angina in patients with normal coronary arteries
}

\author{
Authors: Haseeb Rahman, ${ }^{\mathrm{A}}$ Ozan Demir, ${ }^{\mathrm{A}}$ Matthew Ryan, ${ }^{\mathrm{A}}$ Hannah McConkey, ${ }^{\mathrm{A}}$ Howard Ellis, ${ }^{\mathrm{A}}$ Cian Scannell, ${ }^{\mathrm{A}}$ \\ Amedeo Chiribiri, ${ }^{A}$ Andrew Webb ${ }^{A}$ and Divaka Perera ${ }^{A}$
}

\section{Background}

Forty per cent of patients undergoing angiography to investigate exertional chest pain have normal coronary arteries. While described for nearly half a century, this condition has remained a mechanistic enigma. ${ }^{1-2}$ Diminished coronary blood flow augmentation to a pharmacological vasodilator, or coronary microvascular dysfunction (MVD), portends a greater risk of major adverse cardiovascular events. ${ }^{3-4}$ However, patients report symptoms during physical exercise, and the response to pharmacological 'stress' and physical exercise differ in the healthy heart. ${ }^{5}$ Moreover, it is unclear whether MVD is confined to the coronary circulation or a generalised disorder in myocardial and systemic blood flow during stress.

\section{Aims}

To identify whether patients with MVD have abnormal coronary blood flow during physical exercise, generalised systemic endothelial dysfunction and abnormal global myocardial blood flow during stress.

\section{Method}

Patients with angina and unobstructed coronary arteries underwent simultaneous acquisition of intra-coronary pressure and flow during rest, supine bicycle exercise and pharmacological vasodilatation with adenosine (hyperaemia), in the catheter laboratory. Coronary flow reserve (CFR) was calculated as hyperaemic coronary blood flow (CBF) / resting $\mathrm{CBF}^{6}$ Wave intensity analysis quantified the proportion of accelerating wave energy (perfusion efficiency), a measure of the dynamic interaction between the contracting myocardium and interweaving coronary vasculature during the cardiac cycle, or cardiac-coronary coupling. ${ }^{5}$ Forearm blood flow ratio (FBF) was assessed to acetylcholine and $N^{\mathrm{G}}$-monomethyl-L-arginine (L-NMMA) infusions, an endothelial-dependent dilator and nitric oxide synthase inhibitor. ${ }^{7}$ Global myocardial blood flow and subendocardial:subepicardial perfusion ratio (endo/ epi) were quantified using 3-Tesla cardiac magnetic resonance imaging (MRI) during hyperaemia and rest; inducible ischaemia

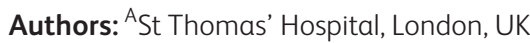

was defined as hyperaemic endo/epi<1.0. ${ }^{8}$ Myocardial perfusion reserve (MPR) was calculated as hyperaemic myocardial blood flow / resting myocardial blood flow. ${ }^{9}$ Patients were classified as having MVD if CFR $<2.5$ and controls if $C F R \geq 2.5$, with researchers blinded to the classification. ${ }^{10}$

\section{Results}

A total of 95 patients were enrolled ( $57 \pm 10$ years, $81 \%$ women); 52 were classified as having MVD and 43 as controls. Microvascular resistance (MR) and CBF during peak exercise were similar in MVD and controls ( $4.5 \pm 1.6$ vs $4.7 \pm 1.6 \mathrm{mmHg}$ / $\mathrm{cm} / \mathrm{s}$ and $30 \pm 10$ vs $27 \pm 8 \mathrm{~cm} / \mathrm{s} ; \mathrm{p}=0.68$ and $\mathrm{p}=0.15)$. However, patients with MVD had higher systolic blood pressure and rate-pressure product $(172 \pm 29$ vs $155 \pm 29 \mathrm{mmHg}$ and 20,486 vs 17,550 beats per minute ${ }^{\star} \mathrm{mmHg}$; both $\mathrm{p}=0.02$ ). From rest to stress coronary perfusion efficiency improved in controls, whereas a paradoxical reduction occurred in those with MVD ( $59 \pm 11 \%$ to $65 \pm 14 \%$; $\mathrm{p}=0.02$ vs $61 \pm 12 \%$ to $44 \pm 10 \%$; $<<0.001$; Fig 1). Patients with MVD had attenuated FBF augmentation to acetylcholine and exaggerated reduction to L-NMMA (3.6 \pm 1.8 vs $4.5 \pm 2.0$ and $0.53 \pm 0.14$ vs $0.78 \pm 0.09 ; \mathrm{p}=0.02$ and $\mathrm{p}<0.001)$.

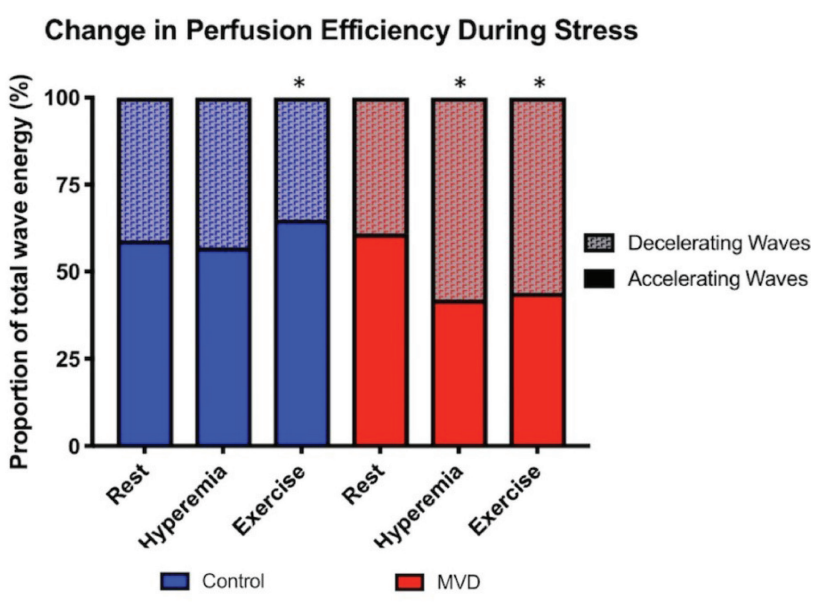

$* p<0.05$ (paired analysis assessing change from rest)

Fig 1. Changes in coronary perfusion efficiency (a measure of cardiaccoronary coupling) from rest to stress. MVD = microvascular dysfunction. 


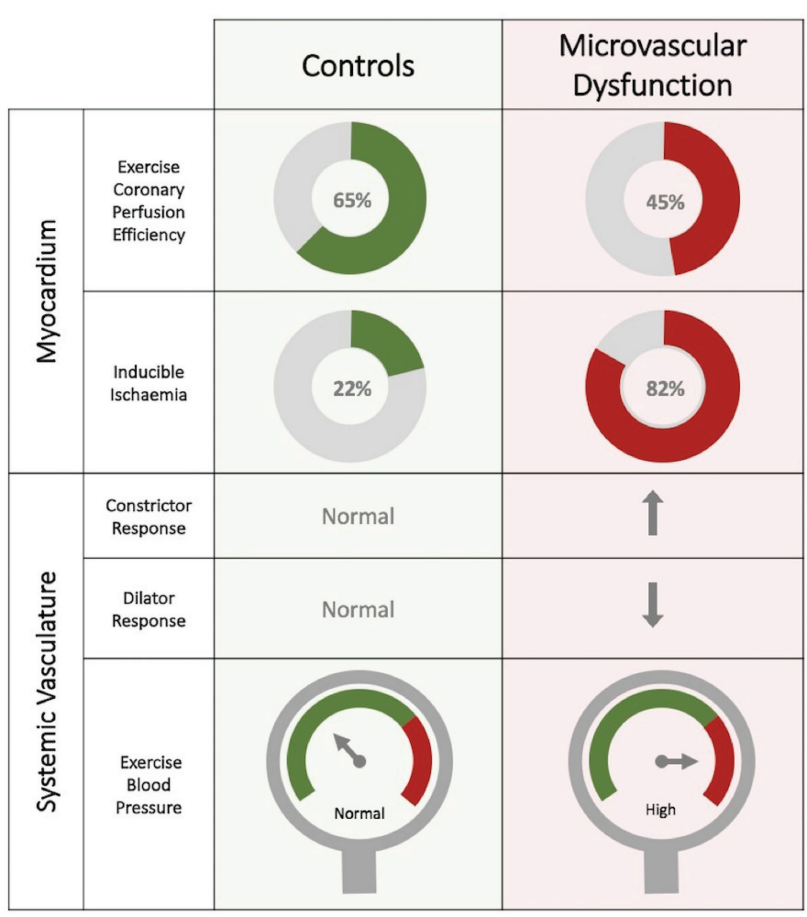

Fig 2. Summary of cardiac and systemic responses to stress in microvascular dysfunction compared with controls.

Those with MVD had a higher rate of inducible myocardial ischaemia and reduced MPR ( $22 \%$ vs $82 \%$ and $2.0 \pm 0.4$ vs $2.7 \pm 0.5$; both $\mathrm{p}<0.001)$.

\section{Conclusions}

Compared with controls, MVD is associated with abnormal cardiac-coronary coupling during exercise, systemic endothelial dysfunction and hypertension with resultant increased myocardial oxygen demand. These pathophysiological changes act in concert to produce global myocardial ischaemia during stress and may underlie the higher incidence of cardiovascular morbidity observed in this population (Fig 2). The nitric oxide synthase pathway may represent a novel therapeutic target and should be the subject of future work; currently no disease-modifying therapy exists specifically for MVD.

\section{Conflicts of interest}

None declared.

\section{References}

1 Patel MR, Peterson ED, Dai D et al. Low diagnostic yield of elective coronary angiography. N Engl J Med 2010;362:886-95.

2 Likoff W, Segal BL, Kasparian H. Paradox of normal selective coronary arteriograms in patients considered to have unmistakable coronary heart disease. N Engl J Med 1967;276:1063-6.

3 Pepine CJ, Anderson RD, Sharaf BL et al. Coronary microvascular reactivity to adenosine predicts adverse outcome in women evaluated for suspected ischemia: results from the National Heart, Lung and Blood Institute. WISE (Women's Ischemia Syndrome Evaluation) study. J Am Coll Cardiol 2010;55:2825-32.

4 Taqueti VR, Shaw LJ, Cook NR et al. Excess cardiovascular risk in women relative to men referred for coronary angiography is associated with severely impaired coronary flow reserve, not obstructive disease. Circulation 2017;135:566-77.

5 Lumley M, Williams R, Asrress KN et al. Coronary physiology during exercise and vasodilation in the healthy heart and in severe aortic stenosis. J Am Coll Cardiol 2016;68:688-97.

6 Gould KL, Lipscomb K, Hamilton GW. Physiologic basis for assessing critical coronary stenosis. Instantaneous flow response and regional distribution during coronary hyperemia as measures of coronary flow reserve. Am J Cardiol 1974;33:87-94.

7 Khan SG, Geer A, Fok HW et al. Impaired neuronal nitric oxide synthase-mediated vasodilator responses to mental stress in essential hypertension. Hypertension 2015;65:903-9.

8 Panting JR, Gatehouse PD, Yang GZ et al. Abnormal subendocardial perfusion in cardiac syndrome $\mathrm{X}$ detected by cardiovascular magnetic resonance imaging. N Engl J Med 2002;346:1948-53.

9 Schuster A, Sinclair M, Zarinabad N et al. A quantitative high resolution voxel-wise assessment of myocardial blood flow from contrast-enhanced first-pass magnetic resonance perfusion imaging: microsphere validation in a magnetic resonance compatible free beating explanted pig heart model. Eur Heart J Cardiovasc Imaging 2015;16:1082-92.

10 Ong P, Camici PG, Beltrame JF et al. International standardization of diagnostic criteria for microvascular angina. Int J Cardiol 2018;250:16-20. 